\title{
Role of GPER in the anterior pituitary gland focusing on lactotroph function
}

\author{
María Andrea Camilletti ${ }^{1}$, Alejandra Abeledo-Machado ${ }^{1}$, Jimena Ferraris², Pablo A Pérez ${ }^{3}$, Erika Y Faraoni', \\ Daniel Pisera², Silvina Gutierrez ${ }^{3}$ and Graciela Díaz-Torga1
}

1Instituto de Biología y Medicina Experimental, Consejo Nacional de Investigaciones Científicas y Técnicas, Buenos Aires, Argentina ${ }^{2}$ Instituto de Investigaciones Biomédicas, Facultad de Medicina, Universidad de Buenos Aires-CONICET, Buenos Aires, Argentina ${ }^{3}$ Centro de Microscopia Electrónica, Instituto de Investigaciones en Ciencias de la Salud (INICSA-CONICET), Facultad de Ciencias Medicas, Universidad Nacional de Córdoba, Córdoba, Argentina

Correspondence should be addressed to G Díaz-Torga: gdiaz@ibyme.conicet.gov.ar

\begin{abstract}
Ovarian steroids control a variety of physiological functions. They exert actions through classical nuclear steroid receptors, but rapid non-genomic actions through specific membrane steroid receptors have been also described. In this study, we demonstrate that the G-protein-coupled estrogen receptor (GPER) is expressed in the rat pituitary gland and, at a high level, in the lactotroph population. Our results revealed that $\sim 40 \%$ of the anterior pituitary cells are GPER positive and $\sim 35 \%$ of the lactotrophs are GPER positive. By immunocytochemical and immuno-electron-microscopy studies, we demonstrated that GPER is localized in the plasmatic membrane but is also associated to the endoplasmic reticulum in rat lactotrophs. Moreover, we found that local Gper expression is regulated negatively by $17 \beta$-estradiol (E2) and progesterone (P4) and fluctuates during the estrus cycle, being minimal in proestrus. Interestingly, lack of ovarian steroids after an ovariectomy (OVX) significantly increased pituitary GPER expression specifically in the three morphologically different subtypes of lactotrophs. We found a rapid estradiol stimulatory effect on PRL secretion mediated by GPER, both in vitro and ex vivo, using a GPER agonist G1, and this effect was prevented by the GPER antagonist G36, demonstrating a novel role for this receptor. Then, the increased pituitary GPER expression after OVX could lead to alterations in the pituitary function as all three lactotroph subtypes are target of GPER ligand and could be involved in the PRL secretion mediated by GPER. Therefore, it should be taken into consideration in the response of the gland to an eventual hormone replacement therapy.
\end{abstract}

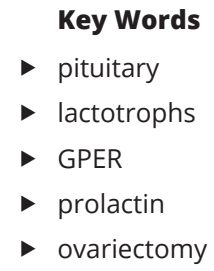

Journal of Endocrinology (2019) 240, 99-110

\section{Introduction}

The involvement of estrogens in the control of pituitary function has been extensively studied (reviewed in Seilicovich 2010). Initially, estradiol was described to induce lactotroph proliferation through $\mathrm{ER} \alpha$; however, apoptotic (Zarate et al. 2009) and antiproliferative (Perez et al. 2015) actions of estradiol in anterior pituitary cells were also demonstrated. These opposite effects depend on the duration of the stimuli, the receptor subtype involved, and receptor subcellular localization. For example, nuclear ER $\alpha$ may trigger lactotroph proliferation, whereas membrane-associated ER $\alpha$ was described to mediate antimitogenic (Gutierrez et al. 2008) and apoptotic effects (Zarate et al. 2009). On the other hand, ER $\beta$ receptors, expressed in the lactotroph 
population (Mitchner et al. 1998), are also able to mediate antiproliferative estradiol actions (Perez et al. 2015).

There is substantial evidence that estradiol exerts rapid non-genomic effects initiated at the cell surface through binding to membrane estrogen receptors (Kelly \& Levin 2001, Levin \& Hammes 2016). Although it was demonstrated that membrane-initiated signaling could be mediated by the classic receptors ER $\alpha$ and ER $\beta$ trafficked to the cell membrane (Zhang et al. 2011, 2012, Zarate et al. 2012, Micevych et al. 2017), the involvement of the 7-transmembrane G proteincoupled estrogen receptor (GPER, formerly named GPR30) in estradiol-induced rapid, non-genomic events has been in the spotlight during the last decade (Maggiolini \& Picard 2010, Zimmerman et al. 2016, De Francesco et al. 2017, Thomas 2017, Fredette et al. 2018).

It has been proposed that GPER collaborates with membrane ER $\alpha$ signaling (Levin 2009). However, there are numerous studies demonstrating specific-GPER function in estradiol-induced non-genomic events in ER-negative cells (Filardo et al. 2000, 2002, Thomas et al. 2005), as well as studies performed in GPER KO mice (Martensson et al. 2009, Prossnitz \& Hathaway 2015) which clearly support the idea that GPER can act as a 'stand-alone' receptor.

GPER, a transmembrane receptor belonging to the GPCR family, was first identified in human breast cancer cells (Filardo et al. 2000), but was later found to be expressed ubiquitously, even in the rat brain and pituitary (Brailoiu et al. 2007, Hazell et al. 2009, Rudolf \& Kadokawa 2013). Although previous reports have provided strong evidence of GPER expression in the pituitary gland, most of these studies focused on gonadotroph cells (Brailoiu et al. 2007, Hazell et al. 2009), meanwhile GPER involvement in the physiology and pathology of the lactotroph population remains to be elucidated.

In the present study, we examined the expression and localization of GPER in the lactotroph population, the local regulation of this receptor by estradiol and progesterone, as well as the local alterations induced in GPER expression in the anterior pituitary gland after ovariectomy. In addition, using pharmacological tools (GPER agonist and antagonist) the involvement of GPER in the regulation of PRL release was studied in vitro and $e x$ vivo, in the GH3 cell line and in rat pituitaries respectively.

\section{Materials and methods}

\section{Animals}

Adult Sprague-Dawley (SD) rats (3-month old, 250 $\pm 30 \mathrm{~g}$ ) were maintained at $25 \pm 2^{\circ} \mathrm{C}$ and $12 \mathrm{~h}$ light-dark cycle,

(c) 2019 Society for Endocrinology Published by Bioscientifica Ltd. Printed in Great Britain lights 07:00-19:00 h. The animals were provided with food and water ad libitum. All the animal procedures were carried out in accordance with the National Institutes of Health guidelines for animal research (8th ed. 2010, NRC, USA) and the European Communities Council Directive of November 2010 (2010/63/UE) and approved by Institute of Biology and Experimental Medicine Animal Care and Use Committee (CICUAL).

SD female rats were ovariectomized (OVX) under anesthesia (Ketamine $50 \mathrm{mg} / \mathrm{kg}+$ Xylazine $10 \mathrm{mg}$, i.p.) as previously described (Ferraris et al. 2014). Two weeks after surgery, animals were killed by decapitation and anterior pituitaries were carefully excised and the neurohypophysis was removed. In addition, cycling rats were monitored daily by vaginal smears, during $4-5$ day estrous cycles, and killed at diestrus, proestrus or estrus. Control female rats were used at diestrus. Anterior pituitary glands were kept in Dulbecco Eagle's Modified Medium (DMEM) (SigmaAldrich) or Trizol Reagent (Ambion, Life Technologies) at $-70^{\circ} \mathrm{C}$ until assays were conducted. For immunogold electron microscopy, anterior pituitaries from female rats in diestrus and OVX rats were collected in a mixture of $4 \% \mathrm{v} / \mathrm{v}$ formaldehyde, $1.5 \% \mathrm{v} / \mathrm{v}$ glutaraldehyde and $0.1 \mathrm{M}$ cacodylate buffer and processed as described below.

\section{In vivo experiments}

Adult female SD rats in diestrus were injected with estradiol valerate $(0.2 \mathrm{mg} / \mathrm{kg} \mathrm{sc}$, Schering, Buenos Aires, Argentina), progesterone $(6.5 \mathrm{mg} / \mathrm{kg} \mathrm{sc}$, Sigma-Aldrich) or castor oil (vehicle, control group). Animals were killed by decapitation after 1,2 or $24 \mathrm{~h}$. Anterior pituitaries were collected in Trizol reagent for qRT-PCR studies.

\section{Ex vivo assay}

Female SD rats in diestrus were killed by decapitation and anterior pituitaries were collected in $250 \mu \mathrm{L}$ of Dulbecco Eagle's Modified Medium (DMEM) supplemented with $15 \% \mathrm{v} / \mathrm{v}$ horse serum (Internegocios, Argentina), 2.5\% $\mathrm{v} / \mathrm{v}$ fetal bovine serum (Natocor, Argentina) and $20 \mu \mathrm{g} / \mathrm{mL}$ of gentamicin (Sigma-Aldrich). Anterior pituitaries were washed and cut in pieces with fresh media and incubated for $2 \mathrm{~h}$ at $37^{\circ} \mathrm{C}$. The GPER receptor antagonist G36 $(1 \mu \mathrm{M})$ or vehicle (ethanol, $1 \mu \mathrm{M}$ ) were added to pituitary explants and incubated for $30 \mathrm{~min}$ at $37^{\circ} \mathrm{C}$. At the end of $30-\mathrm{min}$ period, explants (with or without G36) were stimulated with either vehicle, $17 \beta$-estradiol $(\mathrm{E} 2,100 \mathrm{nM})$ or the GPER receptor agonist $\mathrm{G} 1(100 \mathrm{nM})$ for $15 \mathrm{~min}$ at $37^{\circ} \mathrm{C}$. At the end of the treatment period, secreted medium and 
pituitaries were collected and PRL levels were measured by radioimmunoassay (RIA).

\section{GH3 cell culture}

GH3 clone was established in 1965 by A H Tashjian Jr et al. from a pituitary tumor carried in a 7-month-old female Wistar-Furth rat (Tashjian Jr et al. 1970). GH3 cells (ATCC CCL-82.1, authenticated by STRS analysis) were cultured with DMEM supplemented with $10 \% \mathrm{v} / \mathrm{v}$ fetal bovine serum and $10 \% \mathrm{v} / \mathrm{v}$ horse serum (previously adsorbed), $1 \mathrm{mg} / \mathrm{mL}$ MEM amino acids, $1 \mathrm{mg} / \mathrm{mL}$ glutamine and $100 \mathrm{mg} / \mathrm{mL}$ of gentamicin. Medium was changed every 1-2 days and $0.025 \% \mathrm{v} / \mathrm{v}$ trypsin-EDTA was used to harvest cells.

For experiments, GH3 cells seeded on 24-well culture plates were incubated with DMEM containing vehicle (ethanol, $1 \mu \mathrm{M}$ ) or GPER antagonist (G36, $1 \mu \mathrm{M}$ ) for $30 \mathrm{~min}$. Then, cells were incubated with $17 \beta$-estradiol (E2, $10 \mathrm{nM})$ or GPER agonist $(\mathrm{G} 1,1 \mu \mathrm{M})$ alone or in combination with G36 for additional $15 \mathrm{~min}$. GH3 cells incubated with vehicle (Ethanol, $1 \mu \mathrm{M}$ ) were used as controls. After experimental treatments, medium was collected and stored at $-70^{\circ} \mathrm{C}$ until rat prolactin radioimmunoassays (rPRL RIA) were performed.

\section{Rat prolactin radioimmunoassay (rPRL RIA)}

PRL levels were measured by RIA using reagents provided by the National Institute of Diabetes and Digestive and Kidney Diseases National Hormone and Pituitary Program (NHPP) (Dr A F Parlow, NHPP, Torrance, CA, USA). Results are expressed as $\mathrm{ng} / \mathrm{mL}$ in terms of referent preparation 3 (RP3). Intra- and inter-assay coefficients of variation were 6.7 and $11.9 \%$, respectively.

\section{Quantitative real-time RT-PCR (qRT-PCR)}

Anterior pituitaries from different experimental groups were collected in TRIzol reagent. Total RNA was isolated according to the manufacturer's protocol as described in Faraoni et al. (2017). Reverse transcription was performed using $1 \mu \mathrm{g}$ of total RNA and the resulting cDNA was used for qRT-PCR analysis. A working solution of cDNA was prepared by adding $5 \mu \mathrm{L}$ of samples diluted 1:20 with RNasefree water to a $5 \mu \mathrm{L}$ master mix containing $2 \mu \mathrm{L}$ EVA green qPCR mix (Solis BioDyne, Estonia) and $0.5 \mu \mathrm{M}$ of specific primers for Gper: 5'-ACGCTCAAGGCAGTCATACC-3' (sense); 5'-CTCCCCTGTCCGTTTTCCTC-3' (antisense). To determine the appropriate housekeeping gene as an internal control to normalize the differences in the amount of starting template between samples, two reference genes were evaluated: the $60 \mathrm{~S}$ ribosomal protein L38 (Rpl38): 5'-GTTCGGTGCTCGCTCCTGT-3' (sense) and 5'-CAGATTTGGCATCCTTCCGC-3' (antisense); and Cyclophilin B (Cypb): 5'-GACCCTCCGTGGCCAACGAT-3' (sense) and 5'-GTCACTCGTCCTACAGGTTCGTCTC-3' (antisense). qPCR efficiency of each pair of primers was tested using serially diluted samples and was established by means of calibration curves. Amplification efficiency was determined from the slope of the log-linear portion of the calibration curve. Specifically, PCR efficiency was calculated as $10^{(-1 / \text { slope })}-1$, when the logarithm of the initial template concentration was plotted on the $x$ axis and $\mathrm{Ct}$ was plotted on the $y$ axis. All primers showed similar efficiencies, approximately 95-100\%. Rpl38 was selected as the most proper housekeeping gene due to the parallelism presented between its slope of the regression line (and consequently on the value of the correlation coefficient) with the Gper slope. Table 1 shows average of Ct values obtained in the in vivo treatment with estradiol showing stable expression levels of Rpl38 regardless of the experimental conditions, ensuring a proper normalization within the samples and a robust q-RT-PCR analysis. Relative fold change in target mRNAs was quantified using the $2^{-\Delta \Delta \mathrm{Ct}}$ method, where $\Delta \mathrm{Ct}$ was determined by subtracting the average control $\Delta \mathrm{Ct}$ from the $\Delta \mathrm{Ct}$ of the sample. Each $\Delta \mathrm{Ct}$ was calculated as by substracting the Cts of Rpl38 from the Gper Cts. All cDNA samples were assayed in duplicate for each gene and melt curve analysis was performed to ensure specificity of amplification.

\section{Immunostaining by confocal laser scanning microscopy}

Pituitaries from 3-month-old female SD rats in diestrus were removed immediately after euthanasia and the pituitary cells were dispersed and seeded on glass coverslips $(13 \mathrm{~mm})$ at a density of $2.5 \times 10^{4}$ cells/well. Then, the cells were maintained in DMEM supplemented with $4 \% \mathrm{v} / \mathrm{v}$ fetal calf serum and $8 \% \mathrm{v} / \mathrm{v}$ horse serum (Gibco) in an

Table 1 Average of Ct values showing stable expression of Rp/38 within samples.

\begin{tabular}{|c|c|c|}
\hline Ct values $(\bar{X})$ & Rp/38 & Gper \\
\hline Diestrus & 24.44 & 28.43 \\
\hline $\mathrm{E} 21 \mathrm{~h}$ & 24.16 & 28.31 \\
\hline E2 $2 \mathrm{~h}$ & 24.34 & 29.43 \\
\hline E2 $24 \mathrm{~h}$ & 24.22 & 30.07 \\
\hline
\end{tabular}


incubator with a humidified atmosphere of $5 \% \mathrm{CO}_{2}$ and $95 \%$ air at $37^{\circ} \mathrm{C}$ for 3 days, and finally were fixed in $4 \%$ $\mathrm{v} / \mathrm{v}$ formaldehyde.

For GPER detection, dispersed pituitary cells in coverslips were permeabilized with $0.5 \% \mathrm{v} / \mathrm{v}$ Triton $\mathrm{X}-100 / \mathrm{PBS}$, blocked for $1 \mathrm{~h}$ in 5\% PBS-BSA, incubated overnight in primary antibody (anti-rat GPER, ab39742, Abcam, 1:100) and exposed to Alexa 594 anti-rabbit secondary antibody (Invitrogen, 1:1000) for $1 \mathrm{~h}$. Then, the cells were blocked for $1 \mathrm{~h}$ in 5\% PBS-BSA, incubated with guinea pig antibody directed against rat PRL or rat LH or rat GH (1:1000, Dr A Parlow, NHPP, Torrance, CA, USA) and further incubated with Alexa 488 anti-guinea pig secondary antibody (Invitrogen, 1:1000) for $1 \mathrm{~h}$. The glass coverslips were mounted with fluoromount (Sigma) containing DAPI. Negative controls were carried out incubating the coverslips with the corresponding normal serum, instead of primary antibody or with antibody dilution plus five-fold excess of the control peptide antigen (GPER Peptide, ab41565, Abcam) overnight at $4^{\circ} \mathrm{C}$. Images were obtained using the inverted confocal laser scanning microscope FluoView FV 1000 (Olympus). The analysis of confocal microscopy images was performed using the software FV10-ASW 1.6 Viewer. Briefly, the presence of GPER in GH3 cells was evaluated by immunostaining as described above. GH3 cells $\left(2 \times 10^{5}\right.$ cells per well $)$ were seeded onto glass coverslips in 24-well tissue culture plates and fixed with $4 \% \mathrm{v} / \mathrm{v}$ paraformaldehyde (PFA) in PBS for 20 min. After cell permeabilization and 1-h blocking in a humidified chamber, cells were incubated with GPER antibody (anti-rat GPER, ab39742, Abcam, 1:50) and with an Alexa Fluor 488 goat anti-rabbit secondary antibody (1:100) for $1 \mathrm{~h}$ at room temperature. Cells were stained with DAPI and mounted with Vectashield. Then, cells were visualized in a fluorescence light microscope (Axiophot, Carl Zeiss, Jena, Germany).

\section{Immunogold electron microscopy}

The subcellular localization of GPER in lactotroph cells was determined by applying a labeling post-embedding protocol. Pituitary glands from female rats at diestrus stage or OVX rats were fixed in a mixture of $4 \% \mathrm{v} / \mathrm{v}$ formaldehyde, $1.5 \% \mathrm{v} / \mathrm{v}$ glutaraldehyde and $0.1 \mathrm{M}$ cacodylate buffer, $\mathrm{pH}$ 7.3, at room temperature, with osmiun fixation being omitted. After dehydration and embedding in LR White (London Resin, UK), thin sections were cut using a JEOL ultramicrotome with a diamond knife. Then, the grids were labeled for GPER overnight at $4^{\circ} \mathrm{C}$ (anti-rat GPER, ab39742, Abcam, 1:50), washed and incubated with anti-rabbit secondary antibody conjugated to $15 \mathrm{~nm}$ colloidal gold particles (1:18; Electron Microscopy Sciences; Hatfield, USA). To confirm that lactotroph cells expressed GPER, ultrastructural immunocytochemistry for PRL was performed. Thin sections were incubated overnight at $4^{\circ} \mathrm{C}$ with antisera raised against rat PRL diluted 1:5000 (NIHDDK, Bethesda, MD, USA), washed and incubated with anti-rabbit secondary antibody conjugated to $5 \mathrm{~nm}$ colloidal gold particles (1:50; Electron Microscopy Sciences; Hatfield, USA). To validate the specificity of the immunostaining, controls were performed with $1 \% \mathrm{v} / \mathrm{v}$ BSA in PBS instead of primary antiserum. Then, sections were stained with an aqueous uranyl acetate saturate solution, examined in a Zeiss LEO 906-E electron microscope, and photographed with a megaview III camera.

\section{Flow cytometry}

Control and OVX female rats were killed by decapitation and anterior pituitary glands were removed within minutes and collected in $1000 \mu \mathrm{L}$ of DMEM supplemented and processed as previously described in Ferraris et al. (2014). Cell viability, as assessed by trypan blue exclusion, was over 95\%. Cells were fixed using PFA $0.2 \%$ for $15 \mathrm{~min}$ at room temperature, washed and resuspended in PBS. Then, after permeabilization of the cells with saponinePBS $0.2 \% \mathrm{w} / \mathrm{v}$, washing and centrifuging, immunostaining of GPER-positive cells and of lactotrophs was performed using a rabbit anti-rat GPER $(1 \mu \mathrm{g} / \mathrm{mL})$ and a guinea pig antiserum directed against rat PRL (1:2000) (Dr A Parlow, NHPP, Torrance, CA, USA) for $1 \mathrm{~h}$ at $37^{\circ} \mathrm{C}$. Cells were then washed in PBS and incubated with goat PE-conjugated anti-rabbit (Chemicon International, Temecula, CA, USA) (1:67) and donkey FITC-conjugated anti-guinea pig antibody (Chemicon International) (1:75) for $40 \mathrm{~min}$ at $37^{\circ} \mathrm{C}$ in slow agitation. Cells incubated with guinea pig serum instead of PRL antiserum and rabbit IgG instead of specific primary antibodies were used as isotype controls. Cells were washed, resuspended in PBS and analyzed by FACS (Zarate et al. 2009). Fluorescence intensity of $\geq 10,000$ gated-cells/tube was analyzed using a FACScalibur (BD). Data was analyzed using WinMdi and FlowJo Softwares.

The experiments $(n=6)$ were performed using two different GPER antibodies to ensure specificity. Similar results were obtained using either a rabbit antibody against rat GPER (sc-48525, Santa Cruz Biotechnology Inc, $5 \mu \mathrm{g} / \mathrm{mL}$ ) or a rabbit anti-rat GPER (ab39742, Abcam, $1 \mu \mathrm{g} / \mathrm{mL})$. 


\section{Statistical analysis}

Results are expressed as mean \pm S.E.M. and the significance levels were chosen at $P<0.05$. Student's $t$ test was used to compare OVX and control group data. Estradiol and progesterone acute treatments were analyzed by a Oneway ANOVA followed by a Tukey's post hoc test. In vitro and ex vivo experiments were repeated three times with at least three replicates, and treatments were compared by a One-way ANOVA followed by a Tukey's post hoc test.

\section{Results}

\section{GPER is expressed in the lactotroph population}

First, in order to establish the localization of GPER in pituitary cells, a double indirect immunofluorescence using confocal microscopy was performed. Our results showed lactotroph cells (immunoreactive to PRL), somatotroph cells $(\mathrm{GH})$ and gonadotroph cells $(\beta \mathrm{LH})$ with a circumferential staining pattern, evidencing the presence of GPER in plasmatic membrane in addition to punctuated diffuse fluorescence signal distributed in the cytoplasm (Fig. 1).

Immunocytochemical controls evaluated the specificity of the primary antiserum, and no immunolabelling was found after the omission of the primary antibody and pre-absorbing the antibody with purified antigen.

Next, to determine the percentage of GPER-positive cells expressing PRL, dispersed and double-immunostained (GPER, PRL) anterior pituitary cells from female rats were analyzed by flow cytometry. Our results revealed that $38.5 \pm 8.4 \%$ were GPER positive among the total anterior pituitary cells (Fig. 2A and B). Interestingly, 39.5 $\pm 9.8 \%$ of the GPER-positive cells were PRL positive, and 35.5 $\pm 3.5 \%$ of the PRL-positive cells were GPER positive (Fig. 2C and D).

\section{Estradiol and progesterone negatively regulates pituitary Gper mRNA expression}

$17 \beta$-Estradiol (E2) and progesterone (P4) typically upregulate or downregulate the expression of their classical receptors according to the tissue and the physiological situation. Then, in order to study E2 and $\mathrm{P} 4$ regulation of pituitary Gper expression, we next performed acute in vivo assays in adult female rats. In vivo treatment with E2 significantly decreased pituitary Gper levels after 2 and $24 \mathrm{~h}$ compared to control rats in diestrus (CTRL), (Fig. 3A). In addition, in vivo treatment with $\mathrm{P} 4$ decreased pituitary Gper expression after $24 \mathrm{~h}$ (Fig. 3B). In accordance, and due to the loss of the control by ovarian steroids, Gper expression was significantly increased in the pituitary gland of OVX adult female rats (Fig. 3C).

In order to evaluate the physiological impact of the regulatory effects of gonadal steroid hormones, Gper mRNA levels were measured in the anterior pituitary gland of female rats at different stages of the estrous cycle. Interestingly, Gper mRNA levels were the lowest on the morning of proestrus, when steroid levels were at their highest (Freeman 1986) (Fig. 3D). Finally, we evaluated putative gender differences, but similar levels of pituitary Gper mRNA were found in male pituitaries when compared with those found in females in diestrus (data not shown).

\section{Ovariectomy increases GPER-positive cells among the lactotroph population}

To examine whether the increased pituitary Gper mRNA expression after OVX (Fig. 3C) was associated to an increase in the protein receptor expression in the lactotroph population, dispersed anterior pituitary cells from controls (diestrus) and OVX rats were doubleimmunostained (GPER, PRL) and analyzed by flow cytometry. The cytometry analysis shows that the percentage of GPER-positive anterior pituitary cells significantly increased in OVX rats compared to CTRL rats in diestrus (Fig. 4A). Interestingly, this increment was primarily due to an increase in GPER expression in the lactotroph population (GPER-positive lactotrophs, Fig. 4B) since no differences were found, neither the percentage of GPER-positive non-lactotrophs cells (Fig. 4C) nor the percentage of lactotrophs/total pituitary cells among groups (Fig. 4D).

\section{GPER in different morphological subtypes of lactotrophs}

It is well known that lactotroph population exhibits morphological and functional heterogeneity (Kukstas et al. 1990, De Paul et al. 1997, Christian et al. 2007). In fact, three subtypes of lactotrophs, defined morphologically by electron microscopy (De Paul et al. 1997), could be observed in the anterior pituitary gland from rodents. Interestingly, the proportion of each lactotroph subtype depends, at least partially, on estradiol levels; then it was described that the depletion of estrogen, induced remarkable changes in the lactotroph population.

To the extent of deepening the study of GPER subcellular localization and the lactotroph subtypes expressing GPER, a post-embedding immunolabelling 


\begin{tabular}{l|l|l|r|r|} 
Journal of & M A Camilletti et al. & GPER in rat lactotrophs & $240: 2$ & 104 \\
Endocrinology & & &
\end{tabular}

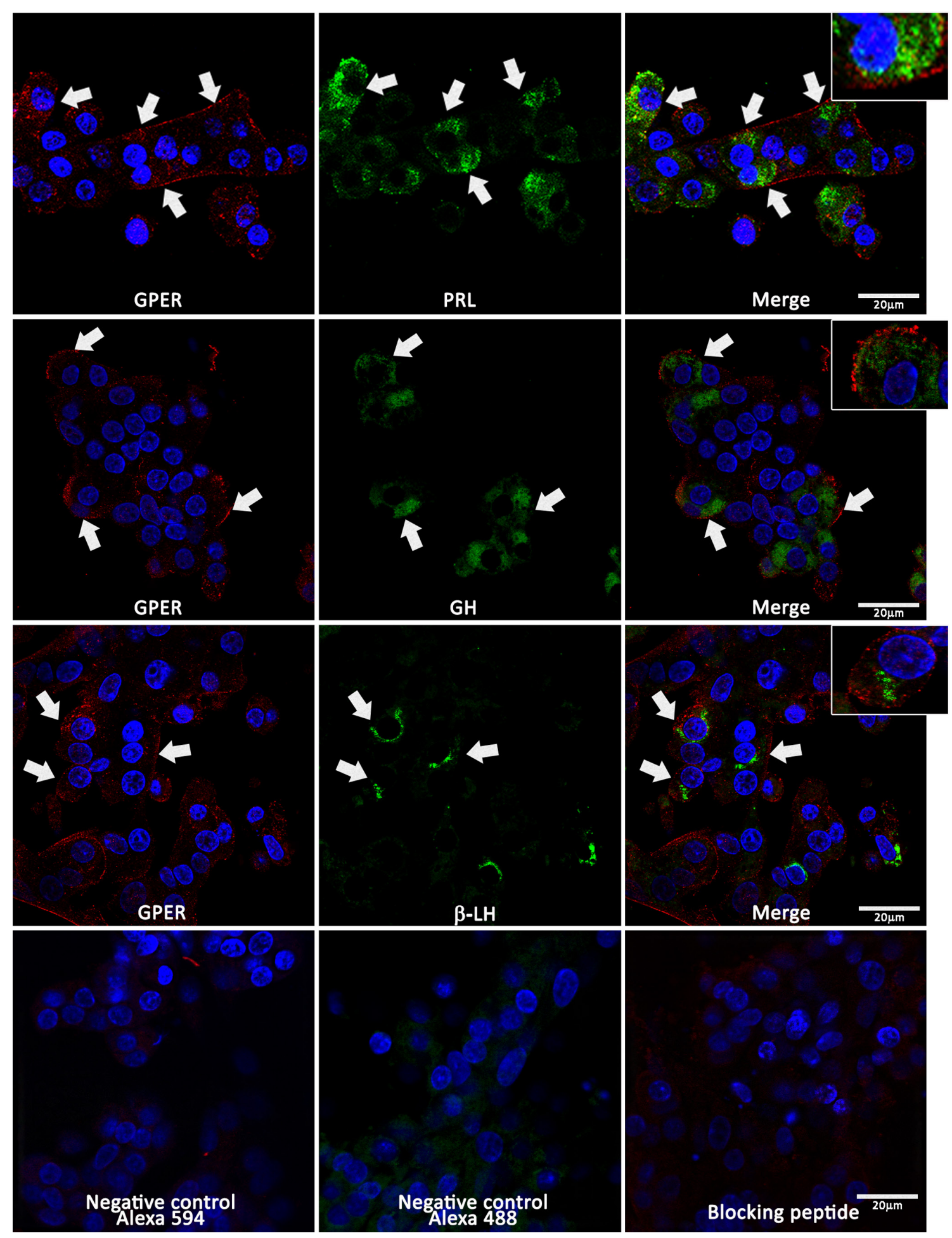

Figure 1

GPER expression in anterior pituitary gland. Anterior pituitary cells from 3-month-old female rats in diestrus were processed for GPER identification. White arrows show lactotrophs (PRL), somatotrophs $(\mathrm{GH})$ and gonadotrophs $(\beta-\mathrm{LH})$ expressing GPER. Nuclei were stained with DAPI. To validate the specificity of the immunostaining, negative controls were performed using blocking peptide or replacing primary antibody with the corresponding normal serum and then incubated with secondary antibody Alexa 594 or Alexa 488. Bar $=20 \mu \mathrm{m}$. 
A
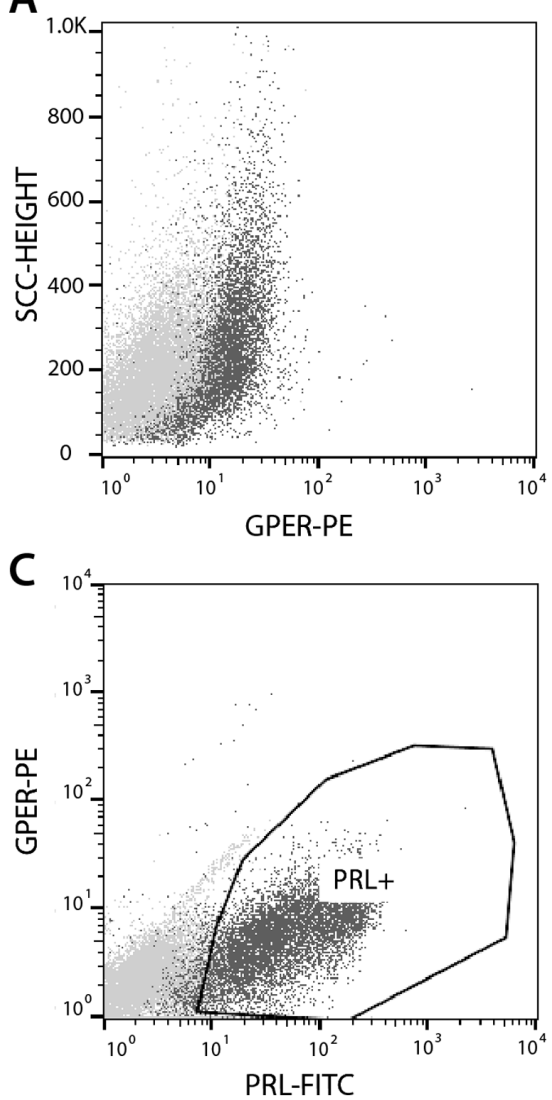

B

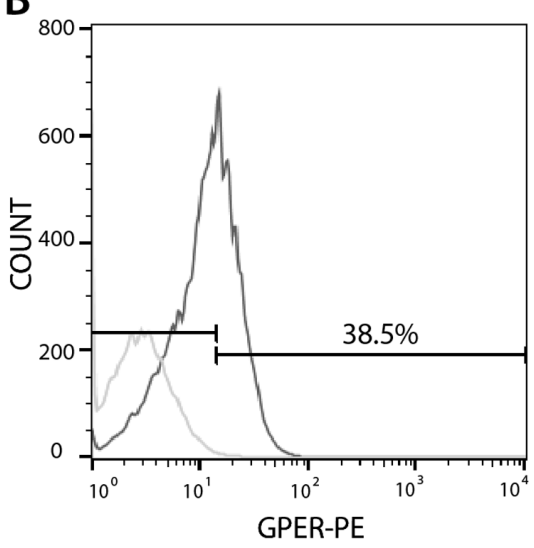

D

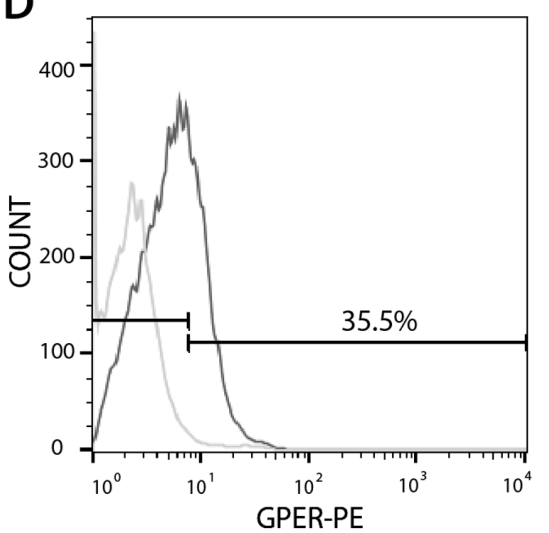

\section{Figure 2}

Flow cytometry analysis of GPER-positive cells in dispersed anterior rat pituitary cells. Dispersed anterior pituitary cells were incubated with anti-GPER antibody (ab39742, Abcam) and analyzed by flow cytometry, $n=8$. Representative dot plots and histograms showing: ( $A$ and $B)$ percentage of total anterior pituitary cells GPER-positive (GPER+) and (C and D) lactotrophs GPER-positive. Gray: isotype controls; gate: lactotrophs. with IgG-colloidal gold for transmission electron microscopy was used. GPER protein was immunolabelled using secondary antibody conjugated to colloidal gold particles of $15 \mathrm{~nm}$ and lactotroph cells were identify immunolabelling PRL with a secondary antibody conjugated to colloidal gold particles of $5 \mathrm{~nm}$. Our results show lactotroph cells expressing GPER, being the subcellular localization in plasmatic membrane, with the gold particles appearing to be attached to the inner surface of the plasmalemma, in rough endoplasmic reticulum and with a few colloidal gold particles being observed in the free cytosol (Fig. 5). In female rats in diestrus, the lactotroph cells were recognized by their irregular, large and polymorphic secretory granules of sizes ranging between 300 and $700 \mathrm{~nm}$ distributed in the cytoplasm and immunolabelled for PRL, typical characteristics of subtype I lactotrophs (Fig. 5A, B and C). In pituitaries from OVX rats, the three morphological subtypes of lactotrophs (I, II and III), were GPER positive. The subtype I was recognized by the irregular and large granules (Fig. 5E), the subtype II were recognized by the medium-sized spherical granules about diameter 200-250 nm (Fig. 5F), and the subtype III was distinguished by their small spherical granules, between 100 and $200 \mathrm{~nm}$ (Fig. 5G).

\section{GPER activation induces PRL release}

\section{GH3 cells}

In order to investigate the involvement of GPER in rapid estradiol effect on prolactin secretion, we performed in vitro assays using the GH3 cell line. First, the GPER protein expression in GH3 cells was demonstrated by ICC (Supplementary Fig. 1, see section on supplementary data given at the end of this article). Then stimulation assays with E2 and GPER agonist and antagonist were performed. After 15 min of stimulation both E2 and G1 increased PRL secretion $\left({ }^{* *} P=0.005\right)$, whereas the GPER antagonist G36 prevented the G1 effect, and partially the E2 stimulation (Fig. 6A) without exerting any per se effects.

\section{Ex vivo assay}

Once stimulation of PRL secretion induced by E2 and G1, involving GPER receptors was confirmed in vitro, this effect was assayed in female rat pituitary explants. As shown in Fig. 6B, both E2 and G1 increased PRL release after 15-min stimulation. These effects were not observed when tissues were pre-incubated with G36, implying that GPER receptors are involved in rapid E2 and G1 stimulation of PRL release. G36 did not modify PRL secretion per se. 
A
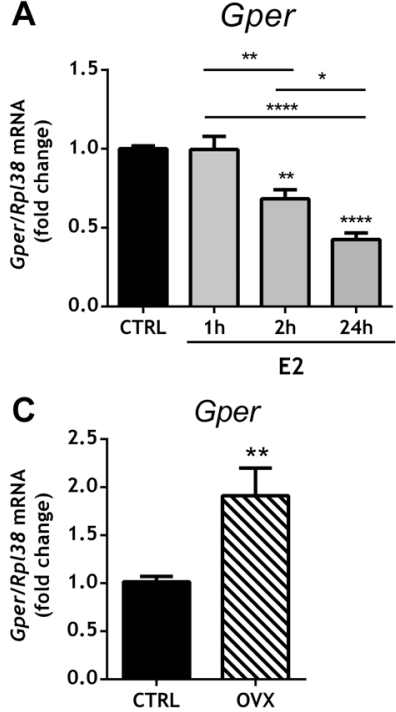
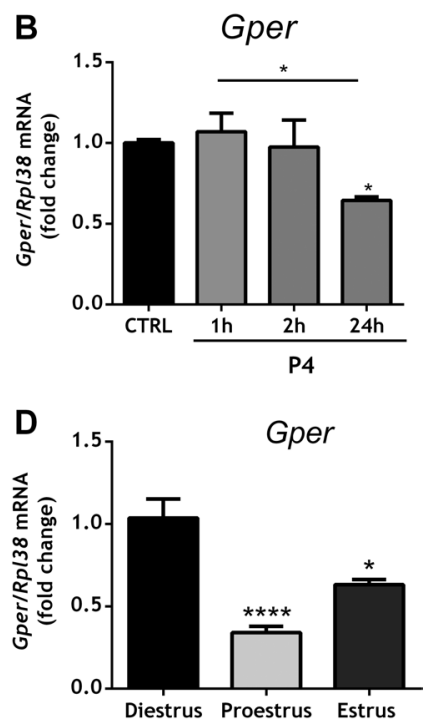

Figure 3

Regulation of Gper mRNA expression in the rat pituitary by E2 and P4. Alterations induced by OVX, and during the estrous cycle. (A) E2 regulation of pituitary Gper mRNA levels was assessed in vivo in female rats in diestrus (E2, $0.2 \mathrm{mg} / \mathrm{kg} \mathrm{BW,} \mathrm{sc)} \mathrm{1,} 2$ and $24 \mathrm{~h}$ or vehicle (CTRL). Pituitary Gper expression was analyzed by qRT-PCR. One-way ANOVA followed by Tukey's post hoc test, $n=5, * * P<0.0052$ E2 $2 \mathrm{~h}$ vS CTRL; $\star \star \star \star * P<0.0001$ E2 $24 \mathrm{~h}$ vs CTRL; $* \star P=0.0059$ E2 $1 \mathrm{~h}$ vs $2 \mathrm{~h} ; * \star \star \star * P<0.0001$ E2 $1 \mathrm{~h}$ vs $24 \mathrm{~h}$ and $* P=0.0239 \mathrm{E} 22 \mathrm{~h}$ vs $24 \mathrm{~h}$. (B) P4 regulation of Gper mRNA levels was studied similarly, in vivo (P4 $6.5 \mathrm{mg} / \mathrm{kg} \mathrm{BW,} \mathrm{sc,} \mathrm{1,} 2$ and $24 \mathrm{~h}$ ) or castor oil (CTRL) in female rats in diestrus. One-way ANOVA followed by Tukey's post hoc test, $n=5,{ }^{*} P=0.0484$ P4 $24 \mathrm{~h}$ vs CTRL and ${ }^{*} P=0219 \mathrm{P} 41 \mathrm{~h}$ vs $24 \mathrm{~h}$. (C) The effect of OVX (15 days post-OVX) on pituitary Gper mRNA levels, analyzed by qRT-PCR. Student's $t$ test, $n=6$, $\star \star P=0.0083$ OVX vs control. (D) Gper mRNA levels in pituitaries from cycling rats. One-way ANOVA followed by Tukey's test, $n=5 ; * \star \star P<0.0001$ proestrus vs diestrus; ${ }^{*} P<0.0139$ estrus vs diestrus.

\section{Discussion}

The involvement of estradiol in the control of PRL secretion was widely demonstrated (Mitchner et al. 1998, Seilicovich 2010). Although this effect has been long proposed to be mediated by ER $\alpha$ (Yen et al. 1974, Ben Jonathan et al. 2009), in this study, we provide new evidences that estradiol can rapidly stimulate PRL secretion in a mechanism mediated by GPER in the lactotroph population.

Previous studies have provided strong evidence of GPER expression in the pituitary gland, but focusing on gonadotroph function (Brailoiu et al. 2007, Hazell et al. 2009). For example, Rudolf et al. reported that approximately $50 \%$ of GPER-positive cells express LH in bovine anterior pituitaries. This finding supports the idea that GPER is expressed in non-gonadotroph pituitary cells as well (Rudolf \& Kadokawa 2013). Our present results are in agreement with previous studies, and showed

A
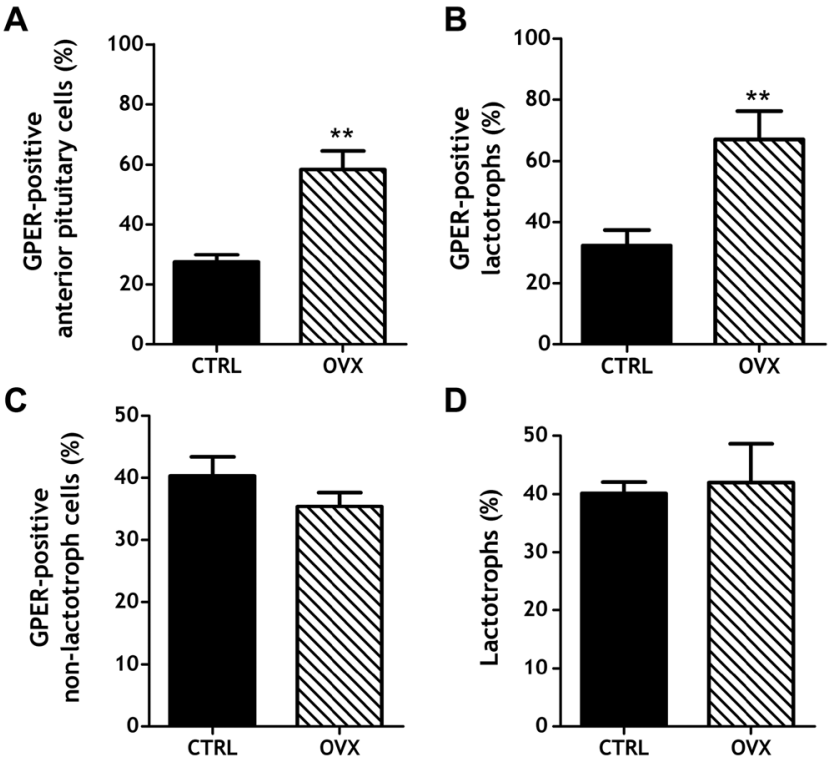

D

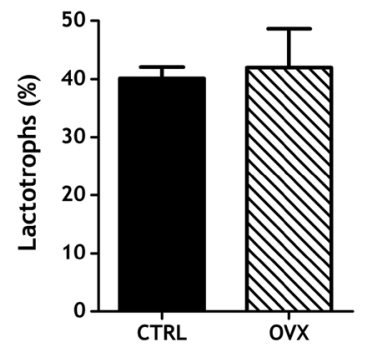

Figure 4

Effect of OVX in GPER expression in lactotrophs. (A) Percentage of GPER+ pituitary cells measured by flow cytometry in OVX rats compared to their control in diestrus: Student's $t$ test, $n=6, * * P=0.0022$. (B) Percentage of GPER+ lactotrophs (PRL + ) population: Student's $t$ test, $n=6, * \star P=0.0063$. (C) Percentage of GPER+ non-lactotrophs (PRL-) pituitary cells, Student's $t$ test, $n=6, P>0.05$. (D) Percentage of lactotrophs in both groups.

Student's $t$ test, $n=6, P>0.05$.

GPER expression in gonadotrophs, lactotrophs and also in somatotrophs. Moreover, the flow cytometry analysis revealed that about the $40 \%$ of the GPER-positive cells are PRL-positive and immunocytochemical and inmunoelectron-microscopy studies strongly demonstrated GPER expression in lactotroph population. The present results, indicating that GPER expression in is primarily localized to the plasma membrane, are consistent with previous findings demonstrating the localization of this receptor in the cell surface of other cell types (Filardo et al. 2000, 2008, Kelly \& Levin 2001, Thomas 2017). In agreement, and using electronic microscopy, we confirmed the subcellular localization of GPER in plasmatic membrane, with gold particles attached to the inner surface of the plasmalemma. However, GPER was also localized in the cytosol. This is in accordance with previous results describing GPER localization in Golgi membranes and in the endoplasmic reticulum in several cancer cell lines. Interestingly, this intracellular localization seems to have a specific role. Revankar et al. demonstrated that activation of intracellular GPER by estradiol induces intracellular calcium mobilization and synthesis of phosphatidylinositol 3,4,5-trisphosphate in the nucleus. Then, GPER was postulated as a plasmatic membrane and intracellular transmembrane estrogen receptor (Revankar et al. 2005, 2007). 

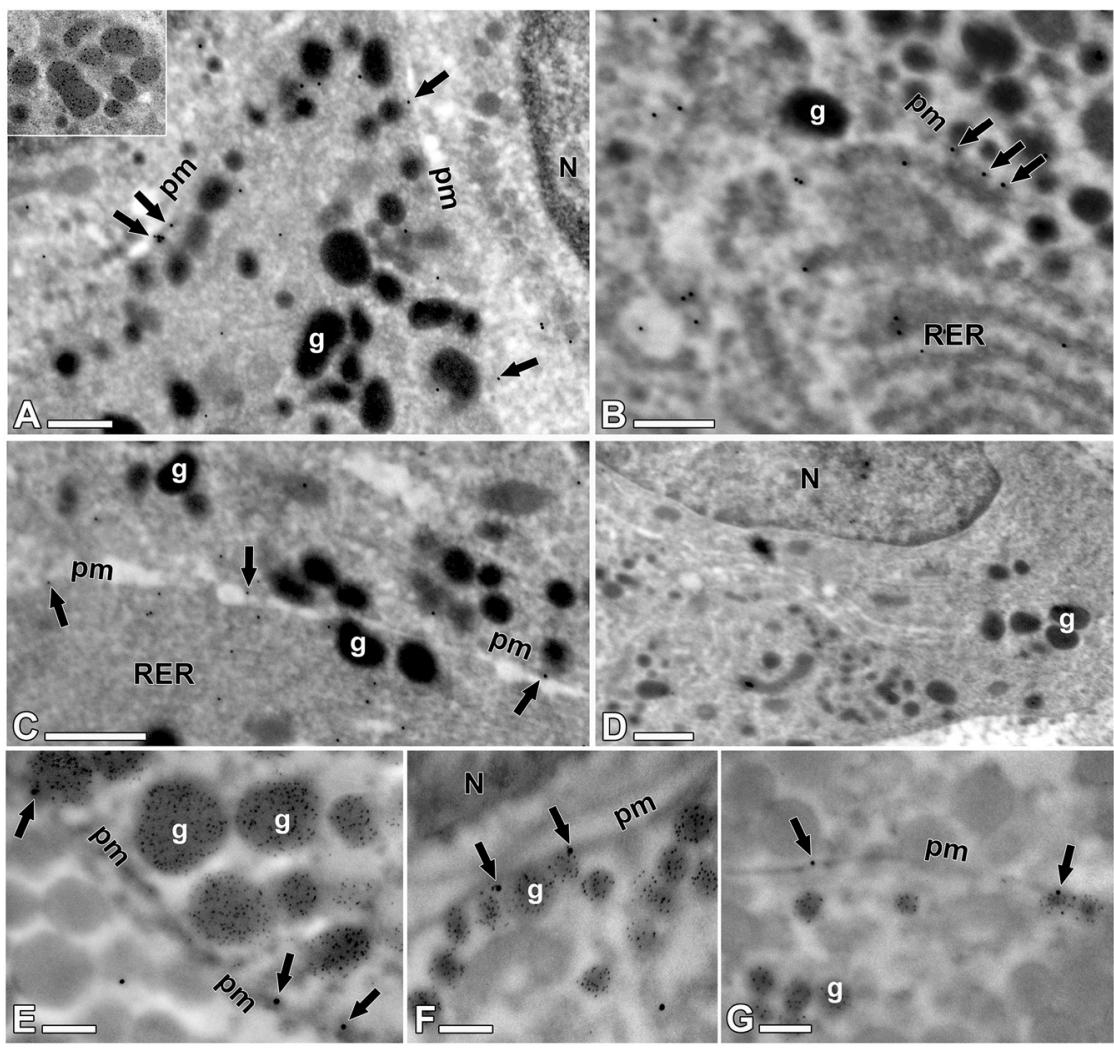

\section{Figure 5}

Immuno-electron-microscopy for GPER. (A, B and C) Subtype I lactotroph cells from female rat at diestrus with gold particles of $15 \mathrm{~nm}$ indicating the presence of GPER in plasmatic membrane (arrows), rough endoplasmic reticulum (RER) and free cytosol. Inset: Irregular, large and polymorphic secretory granules immunolabelled for PRL ( $5 \mathrm{~nm}$ gold particles). (D) Negative control. Bar $=0.5 \mu \mathrm{m} .(E, F$ and $G)$ Lactotroph cells from OVX female rat immunolabelled for GPER with gold particles of $15 \mathrm{~nm}$ (GPER) in plasmatic membrane (arrows). PRL was immunostained with $5 \mathrm{~nm}$ gold particles identifying lactotroph cells with large and irregular secretory granules (E: Subtype I lactotroph), lactotrophs with spherical granules about diameter 200-250 nm (F: Subtype II), and lactotroph cells with small spherical granules, between 100 and $200 \mathrm{~nm}$ (G: Subtype III). N, nucleus; pm, plasmatic membrane; g, secretory granules. Bar $=0.2 \mu \mathrm{m}$.
The biological significance of GPER being highly expressed in rat lactotrophs, suggested a role for this receptor in this cell type population. Previous studies postulated GPER involvement in prolactin secretion: (i) induced by xenoestrogens in the GH3 cell line (Vinas \& Watson 2013) or (ii) an indirect effect activating GPER in hypothalamus (Lebesgue et al. 2009). Regarding the latter, this is particularly relevant considering that a high expression of GPER was found in the paraventricular nucleus and supraoptic nucleus in rats (Brailoiu et al. 2007). In fact, it has been described that GPER agonist G1 administered in vivo into the third ventricle triggers a PRL surge similar in amplitude to the one observed in response to E2 (Lebesgue et al. 2009). In the light of the aforementioned results it may be interesting to study the hypothalamic influence of E2-GPER in the neuroendocrine regulation of proestrus surge of PRL secretion. The complex mechanism is poorly understood and appears to be due to a complex mechanism starting in the hypothalamus, more than a direct estradiol-mediated rapid action in the lactotroph population (Szawka et al. 2007).

Explicit data regarding the role of GPER in normal pituitary lactotrophs is missing. Our present results demonstrate that GPER activation rapidly increases PRL secretion in vitro (in GH3 cell line) and ex vivo (female rat pituitary explants). Moreover, this effect was counteracted when cells or tissues were pre-incubated with G36, a GPER antagonist. Taken together, our results provide the first evidences of a specific role of GPER in rat lactotrophs.

In addition, we found that pituitary Gper expression is negatively regulated by estradiol and progesterone treatments, and, moreover, it changes during the estrous cycle. In consequence, GPER expression (protein and transcript) was found increased after OVX, likely due to the lack of ovarian steroids. In fact, according to the flow cytometry studies with double immunostaining (PRL, GPER), the increase in pituitary GPER expression after OVX was observed specifically in the lactotroph population, as the proportion of GPER-positive cells, and GPER-positive lactotrophs significantly increased in OVX rats compared to controls in diestrus and no differences were found neither in the proportion of non-lactotroph GPER-positive cells nor in the proportion of lactotrophs among groups.

It was previously described that three subtypes of lactotrophs, defined morphologically by electron microscopy, could be observed in the anterior pituitary gland from rodents (De Paul et al. 1997). In our present work, GPER was observed mainly in the subtype I (lactotroph cells), in pituitaries from female rats at diestrus. This is reasonable considering that, in adult 
A

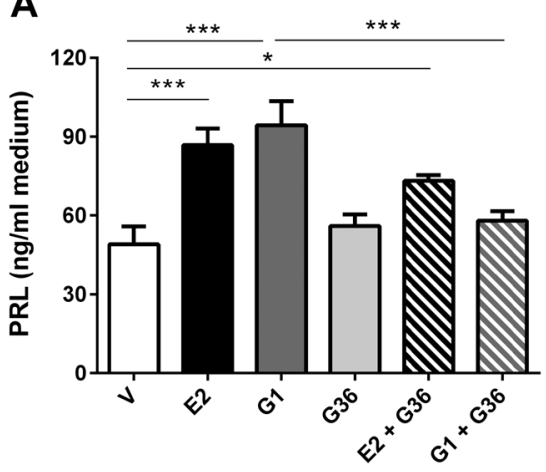

B

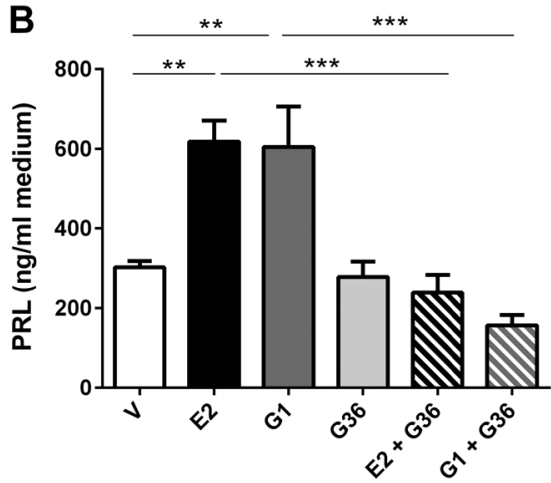

\section{Figure 6}

Effect of E2, G1 and/or G36 on PRL levels in vitro and ex vivo. (A) GH3 cells were incubated with DMEM containing vehicle (V) (ethanol, $1 \mu \mathrm{M}$ ) or $\mathrm{G} 36(1 \mu \mathrm{M})$ for $30 \mathrm{~min}$ and then estradiol $(100 \mathrm{nM})$ or G1 (100 nM) were added alone or in combination with $\mathrm{G} 36$ for $15 \mathrm{~min}$ at $37^{\circ} \mathrm{C}$. After treatments, medium was collected and rat PRL levels were measured by RIA. One-way ANOVA followed by Tukey's post hoc test, $n=3$, three replicates in each set of experiments, $* * * P<0.001$ $\mathrm{E} 2$ vs $\mathrm{V}, * P<0.05 \mathrm{E} 2+\mathrm{G} 36$ vs $\mathrm{V}, * * * P<0.001 \mathrm{G} 1$ vs $V$ and $* * * P<0.001 \mathrm{G} 1$ vs G1 $+\mathrm{G} 36$. (B) SD rats were sacrificed and anterior pituitaries were collected. Explants were incubated 30 min with G36 $(1 \mu \mathrm{M})$ or vehicle (ethanol, $1 \mu \mathrm{M})$ and then estradiol (100 nM) or G1 (100 nM) were added alone or in combination with G36 for 15 min at $37^{\circ} \mathrm{C}$. After treatments, PRL levels were measured by RIA in secreted medium. One-way ANOVA followed by Tukey's post hoc test, $n=3$, three replicates in each set of experiments, $* * P<0.01$ $\mathrm{E} 2$ vs $\mathrm{V}, * * P<0.01 \mathrm{G} 1$ vs $\mathrm{V}, * * * P<0.001 \mathrm{E} 2$ vs $\mathrm{E} 2+\mathrm{G} 36$ and ***P<0.001 G1 vs G1 + G36. female rats, the subtype I represents about the 90\% of the total of lactotroph population, and the subtype II and III account for less than 10\% (Kurosumi et al. 1987). However, when the electron microscopy was performed in pituitary glands from OVX female rats, the GPER expression was found extended to the three lactotroph subtypes, characteristic of this model (pituitaries from OVX rats) where the 35\% of lactotrophs are subtype I, 30\% are subtype II and about 36\% are subtype III (Maldonado \& Aoki 1994).

This result could explain the specific increase of GPERpositive lactotrophs observed in OVX rats compared to controls in diestrus, and moreover, shows that all three lactotroph subtypes are target of GPER ligand and could be involved in the PRL secretion mediated by GPER in OVX rats.

Considering that a rapid estradiol stimulatory effect on PRL secretion mediated by GPER was demonstrated in vitro and in pituitary explants, the elevated expression of GPER observed in the lactotroph population after an OVX, should be taken into consideration in: (i) the use of OVX as animal models, (ii) the response of the gland to an eventual hormone replacement therapy after OVX.

Estrogen replacement therapy is frequently suggested in women after bilateral prophylactic oophorectomy to prevent the potential negative effects of losing of natural hormone production (Watson et al. 2008, Erekson et al. 2013). As the major concern in those patients is the risk of cancer, the impact of the oophorectomy in the pituitary function, with or without hormone replacement therapy, is usually ignored.
Even though our present results do not include the involvement of GPER in lactotroph proliferation, several studies performed in many cancer cell lines and tumors of breast, endometrium, ovaries, thyroid and prostate among others, suggest that high levels of GPER protein expression correlate with increased tumor size and poor outcome, and, moreover, stimulation of GPER with estrogenic compounds such as atrazine, bisphenol A or tamoxifen activates cell proliferation (Prossnitz \& Barton 2011).

In the light of these facts and our present results, it is worth facing future studies to investigate the involvement of GPER in physiological and pathological lactotroph proliferation and the significance of increased expression of GPER observed in lactotrophs after OVX in rats.

\section{Supplementary data}

This is linked to the online version of the paper at https://doi.org/10.1530/ JOE-18-0402.

\section{Declaration of interest}

The authors declare that there is no conflict of interest could be perceived as prejudicing the impartiality of the research reported.

\section{Funding}

This work was supported by the Agencia Nacional de Promoción Científica y Técnica, Buenos Aires, Argentina (grant PICT 2013 N2136 
to G D T; PICT 2016 N0252 to G D T and PICT 2013 N1900 to J F), René Barón Fundation Argentina (to G D T), Williams Fundation Argentina (to G D T) and the Secretaría de Ciencia y Tecnología de la Universidad Nacional de Córdoba (SECyT-UNC 2016 to S G).

\section{Author contribution statement}

M A C, D P, J F, S G and G D T conception and design of research; M A C, AA M, J F, E Y F, P A P and S G performed experiments; M A C, A A M, J F, P A P, S G, D P and G D T analyzed data; M A C, A A M, J F, S G and G D T interpreted results of experiments; M A C, A A M, P A P and S G prepared figures; M A C, S G and G D T drafted manuscript; M A C, A A M, J F, EY F, S G, D P and G D T edited and revised manuscript; M A C, A A M, J F, D P, P A P, S G and G D T approved final version of manuscript.

\section{Acknowledgments}

The authors thank the National Institute of Diabetes and Digestive and Kidney Diseases NHPP and Dr A F Parlow for prolactin RIA kit.

\section{References}

Ben Jonathan N, Chen S, Dunckley JA, LaPensee C \& Kansra S 2009 Estrogen receptor-alpha mediates the epidermal growth factorstimulated prolactin expression and release in lactotrophs. Endocrinology 150 795-802. (https://doi.org/10.1210/en.2008-0756)

Brailoiu E, Dun SL, Brailoiu GC, Mizuo K, Sklar LA, Oprea TI, Prossnitz ER \& Dun NJ 2007 Distribution and characterization of estrogen receptor $\mathrm{G}$ protein-coupled receptor 30 in the rat central nervous system. Journal of Endocrinology 193 311-321. (https://doi.org/10.1677/JOE-07-0017)

Christian HC, Chapman LP \& Morris JF 2007 Thyrotrophin-releasing hormone, vasoactive intestinal peptide, prolactin-releasing peptide and dopamine regulation of prolactin secretion by different lactotroph morphological subtypes in the rat. Journal of Neuroendocrinology 19 605-613. (https://doi.org/10.1111/j.1365-2826.2007.01567.x)

De Francesco EM, Sotgia F, Clarke RB, Lisanti MP \& Maggiolini M 2017 $\mathrm{G}$ protein-coupled receptors at the crossroad between physiologic and pathologic angiogenesis: old paradigms and emerging concepts. International Journal of Molecular Sciences 18 E2713. (https://doi. org/10.3390/ijms18122713)

De Paul AL, Pons P, Aoki A \& Torres AI 1997 Heterogeneity of pituitary lactotrophs: immunocytochemical identification of functional subtypes. Acta Histochemica 99 277-289. (https://doi.org/10.1016/ S0065-1281(97)80022-0)

Erekson EA, Martin DK \& Ratner ES 2013 Oophorectomy: the debate between ovarian conservation and elective oophorectomy. Menopause 20 110-114. (https://doi.org/10.1097/gme.0b013e31825a27ab)

Faraoni EY, Camilletti MA, Abeledo-Machado A, Ratner LD, De Fino F, Huhtaniemi I, Rulli SB \& Diaz-Torga G 2017 Sex differences in the development of prolactinoma in mice overexpressing hCGbeta: role of TGFbeta1. Journal of Endocrinology 232 535-546. (https://doi org/10.1530/JOE-16-0371)

Ferraris J, Zárate S, Jaita G, Boutillon F, Bernadet M, Auffret J, Seilicovich A, Binart N, Goffin V \& Pisera D 2014 Prolactin induces apoptosis of lactotropes in female rodents. PLOS ONE 9 e97383. (https://doi.org/10.1371/journal.pone.0097383)

Filardo EJ, Quinn JA, Bland KI \& Frackelton AR Jr 2000 Estrogen-induced activation of Erk-1 and Erk-2 requires the G protein-coupled receptor homolog, GPR30, and occurs via trans-activation of the epidermal growth factor receptor through release of HB-EGF. Molecular Endocrinology 14 1649-1660. (https://doi.org/10.1210/mend.14.10.0532)
Filardo EJ, Quinn JA, Frackelton AR Jr \& Bland KI 2002 Estrogen action via the G protein-coupled receptor, GPR30: stimulation of adenylyl cyclase and cAMP-mediated attenuation of the epidermal growth factor receptor-to-MAPK signaling axis. Molecular Endocrinology 16 70-84. (https://doi.org/10.1210/mend.16.1.0758)

Filardo EJ, Quinn JA \& Sabo E 2008 Association of the membrane estrogen receptor, GPR30, with breast tumor metastasis and transactivation of the epidermal growth factor receptor. Steroids $\mathbf{7 3}$ 870-873. (https://doi.org/10.1016/j.steroids.2007.12.025)

Fredette NC, Meyer MR \& Prossnitz ER 2018 Role of GPER in estrogendependent nitric oxide formation and vasodilation. Journal of Steroid Biochemistry and Molecular Biology 176 65-72. (https://doi. org/10.1016/j.jsbmb.2017.05.006)

Freeman ME 1986 The ovarian cycle of the rat. In The Physiology of Reproduction, 1st ed., pp 2323-2349. Eds E Knobil \& J Neill. New York, NY, USA: Raven Press, Ltd.

Gutierrez S, De Paul AL, Petiti JP, del Valle SL, Palmeri CM, Soaje M, Orgnero EM \& Torres AI 2008 Estradiol interacts with insulin through membrane receptors to induce an antimitogenic effect on lactotroph cells. Steroids 73 515-527. (https://doi.org/10.1016/j. steroids.2008.01.002)

Hazell GG, Yao ST, Roper JA, Prossnitz ER, O'Carroll AM \& Lolait SJ 2009 Localisation of GPR30, a novel G protein-coupled oestrogen receptor, suggests multiple functions in rodent brain and peripheral tissues. Journal of Endocrinology 202 223-236. (https://doi.org/10.1677/ JOE-09-0066)

Kelly MJ \& Levin ER 2001 Rapid actions of plasma membrane estrogen receptors. Trends in Endocrinology and Metabolism 12 152-156. (https:// doi.org/10.1016/S1043-2760(01)00377-0)

Kukstas LA, Verrier D, Zhang J, Chen C, Israel JM \& Vincent JD 1990 Evidence for a relationship between lactotroph heterogeneity and physiological context. Neurosciences Letters 120 84-86. (https://doi. org/10.1016/0304-3940(90)90173-7)

Kurosumi K, Tanaka S \& Tosaka H 1987 Changing ultrastructures in the estrous cycle and postnatal development of prolactin cells in the rat anterior pituitary as studied by immunogold electron microscopy. Archivum Histologicum Japonicum 50 455-478. (https:// doi.org/10.1679/aohc.50.455)

Lebesgue D, Reyna-Neyra A, Huang X \& Etgen AM 2009 GPR30 differentially regulates short latency responses of luteinising hormone and prolactin secretion to oestradiol. Journal of Neuroendocrinology $\mathbf{2 1}$ 743-752. (https://doi.org/10.1111/j.1365-2826.2009.01893.x)

Levin ER 2009 G protein-coupled receptor 30: estrogen receptor or collaborator? Endocrinology 150 1563-1565. (https://doi.org/10.1210/ en.2008-1759)

Levin ER \& Hammes SR 2016 Nuclear receptors outside the nucleus: extranuclear signalling by steroid receptors. Nature Reviews Molecular Cell Biology 17 783-797. (https://doi.org/10.1038/nrm.2016.122)

Maggiolini M \& Picard D 2010 The unfolding stories of GPR30, a new membrane-bound estrogen receptor. Journal of Endocrinology 204 105-114. (https://doi.org/10.1677/JOE-09-0242)

Maldonado C \& Aoki A 1994 Occurrence of atypical lactotrophs associated with levels of prolactin secretory activity. Biocell 18 83-95.

Martensson UE, Salehi SA, Windahl S, Gomez MF, Swärd K, DaszkiewiczNilsson J, Wendt A, Andersson N, Hellstrand P, Grände PO, et al. 2009 Deletion of the $G$ protein-coupled receptor 30 impairs glucose tolerance, reduces bone growth, increases blood pressure, and eliminates estradiol-stimulated insulin release in female mice. Endocrinology 150 687-698. (https://doi.org/10.1210/en.2008-0623)

Micevych PE, Mermelstein PG \& Sinchak K 2017 Estradiol membraneinitiated signaling in the brain mediates reproduction. Trends in Neurosciences 40 654-666. (https://doi.org/10.1016/j.tins.2017.09.001)

Mitchner NA, Garlick C \& Ben Jonathan N 1998 Cellular distribution and gene regulation of estrogen receptors alpha and beta in the rat pituitary gland. Endocrinology 139 3976-3983. (https://doi. org/10.1210/endo.139.9.6181) 
Perez PA, Petiti JP, Wagner IA, Sabatino ME, Sasso CV, De Paul AL, Torres AI \& Gutierrez S 2015 Inhibitory role of ERbeta on anterior pituitary cell proliferation by controlling the expression of proteins related to cell cycle progression. Molecular and Cellular Endocrinology 415 100-113. (https://doi.org/10.1016/j.mce.2015.08.009)

Prossnitz ER \& Barton M 2011 The G-protein-coupled estrogen receptor GPER in health and disease. Nature Reviews Endocrinology 7 715-726. (https://doi.org/10.1038/nrendo.2011.122)

Prossnitz ER \& Hathaway HJ 2015 What have we learned about GPER function in physiology and disease from knockout mice? Journal of Steroid Biochemistry and Molecular Biology 153 114-126. (https://doi. org/10.1016/j.jsbmb.2015.06.014)

Revankar CM, Cimino DF, Sklar LA, Arterburn JB \& Prossnitz ER 2005 A transmembrane intracellular estrogen receptor mediates rapid cell signaling. Science 307 1625-1630. (https://doi.org/10.1126/ science.1106943)

Revankar CM, Mitchell HD, Field AS, Burai R, Corona C, Ramesh C, Sklar LA, Arterburn JB \& Prossnitz ER 2007 Synthetic estrogen derivatives demonstrate the functionality of intracellular GPR30. ACS Chemical Biology 2 536-544. (https://doi.org/10.1021/cb700072n)

Rudolf FO \& Kadokawa H 2013 Expression of estradiol receptor, GPR30, in bovine anterior pituitary and effects of GPR30 agonist on GnRHinduced LH secretion. Animal Reproduction Science 139 9-17. (https:// doi.org/10.1016/j.anireprosci.2013.04.003)

Seilicovich A 2010 Cell life and death in the anterior pituitary gland: role of oestrogens. Journal of Neuroendocrinology 22 758-764. (https://doi. org/10.1111/j.1365-2826.2010.02010.x)

Szawka RE, Rodovalho GV, Helena CV, Franci CR \& Anselmo-Franci JA 2007 Prolactin secretory surge during estrus coincides with increased dopamine activity in the hypothalamus and preoptic area and is not altered by ovariectomy on proestrus. Brain Research Bulletin $\mathbf{7 3}$ 127-134. (https://doi.org/10.1016/j.brainresbull.2007.03.001)

Tashjian AH Jr, Bancroft FC \& Levine L 1970 Production of both prolactin and growth hormone by clonal strains of rat pituitary tumor cells. Differential effects of hydrocortisone and tissue extracts. Journal of Cell Biology 47 61-70. (https://doi.org/10.1083/ jcb.47.1.61)
Thomas P 2017 Role of G-protein-coupled estrogen receptor (GPER/ GPR30) in maintenance of meiotic arrest in fish oocytes. Journal of Steroid Biochemistry and Molecular Biology 167 153-161. (https://doi. org/10.1016/j.jsbmb.2016.12.005)

Thomas P, Pang Y, Filardo EJ \& Dong J 2005 Identity of an estrogen membrane receptor coupled to a $\mathrm{G}$ protein in human breast cancer cells. Endocrinology 146 624-632. (https://doi.org/10.1210/en.2004-1064)

Vinas R \& Watson CS 2013 Bisphenol S disrupts estradiol-induced nongenomic signaling in a rat pituitary cell line: effects on cell functions. Environmental Health Perspectives 121 352-358. (https://doi. org/10.1289/ehp.1205826)

Watson CS, Jeng YJ \& Kochukov MY 2008 Nongenomic actions of estradiol compared with estrone and estriol in pituitary tumor cell signaling and proliferation. FASEB Journal 22 3328-3336. (https://doi. org/10.1096/fj.08-107672)

Yen SS, Ehara Y \& Siler TM 1974 Augmentation of prolactin secretion by estrogen in hypogonadal women. Journal of Clinical Investigation $\mathbf{5 3}$ 652-655. (https://doi.org/10.1172/JCI107600)

Zarate S, Jaita G, Zaldivar V, Radl DB, Eijo G, Ferraris J, Pisera D \& Seilicovich A 2009 Estrogens exert a rapid apoptotic action in anterior pituitary cells. American Journal of Physiology: Endocrinology and Metabolism 296 E664-E671. (https://doi.org/10.1152/ ajpendo.90785.2008)

Zarate S, Jaita G, Ferraris J, Eijo G, Magri ML, Pisera D \& Seilicovich A 2012 Estrogens induce expression of membrane-associated estrogen receptor alpha isoforms in lactotropes. PLoS ONE 7 e41299. (https:// doi.org/10.1371/journal.pone.0041299)

Zhang XT, Kang LG, Ding L, Vranic S, Gatalica Z \& Wang ZY 2011 A positive feedback loop of ER-alpha36/EGFR promotes malignant growth of ER-negative breast cancer cells. Oncogene 30 770-780. (https://doi.org/10.1038/onc.2010.458)

Zhang XT, Ding L, Kang LG \& Wang ZY 2012 Involvement of ER-alpha36, Src, EGFR and STAT5 in the biphasic estrogen signaling of ER-negative breast cancer cells. Oncology Reports 27 2057-2065.

Zimmerman MA, Budish RA, Kashyap S \& Lindsey SH 2016 GPER-novel membrane oestrogen receptor. Clinical Science 130 1005-1016. (https://doi.org/10.1042/CS20160114)

Received in final form 27 September 2018

Accepted 19 October 2018

Accepted Preprint published online 25 October 2018 (c) 2019 Society for Endocrinology Published by Bioscientifica Ltd. Printed in Great Britain 